\title{
Understanding factors affecting the stability of inline polymer-amended tailings
}

\author{
A Costine CSIRO Mineral Resources, Australia \\ F Benn CSIRO Mineral Resources, Australia \\ P Fawell CSIRO Mineral Resources, Australia \\ M Edraki Sustainable Minerals Institute, Australia \\ T Baumgartl Sustainable Minerals Institute, Australia \\ J Bellwood BASF plc, UK
}

\begin{abstract}
Tailings rehabilitation, using soil-like properties with chemical and physical stability, can be influenced by surface forces on a particle scale and microstructure. Non-homogeneous structures, manifesting as particle aggregation, alter the permeability/porosity and improve the balance of aerated and water-filled pores that then favours plant growth. Polymer flocculation in tailings thickeners yields large, weak aggregates that are sheared in beds and on pumping. While low-level residual structure may remain, sizes are small and downstream polymer impacts are minor. However, high polymer dosages added in-pipe to high-solids streams lead to further water recovery on deposition, and while this process is poorly understood, it gives aggregates that are likely denser and stronger. If such structures persist, they could potentially offer closure and rehabilitation benefits in some applications.

A high-solids (50 wt\%) thickener underflow analogue (kaolin, silt, and fine sand) was treated with anionic polyacrylamide (PAM) polymers at elevated dosages (up to $1,000 \mathrm{~g} \mathrm{t}^{-1}$ ) to establish if aggregate structures created during inline tailings flocculation survive or change over longer-term consolidation. Low and high molecular weight (MW) PAM polymers of fixed anionicity (30\%) were tested. Focused beam reflectance measurement (FBRM) provided real-time monitoring of the aggregation state after polymer addition. The compressibility of the inline flocculated tailings was assessed over an eight week period. Variations in the size-density relationship of aggregate structures were determined over this period using an image analysis technique, revealing that the shorter polymer chains produced denser, more compact structures immediately after deposition, whereas the longer chains resulted in a much slower re-conformation of the partially adsorbed polymer, leading to additional densification over time.

Eight weeks after deposition, inline flocculated tailings produced with the low MW polymer were characterised by a higher compressive yield stress compared with the high MW polymer, consistent with the formation of smaller, more rigid aggregate structures with the shorter chains. The potential impact of such structures on longer-term rehabilitation properties (e.g. metal/metalloid ion adsorption and surface exchange capacity) of the treated tailings is discussed.
\end{abstract}

Keywords: inline flocculated tailings, self-weight consolidation, polymer selection

\section{Introduction}

In-pipe or inline flocculation, where polymer is added at high dosages to thickener underflows, gives additional (likely denser) aggregation, releasing more water on deposition compared to low solids thickening alone (McColl \& Scammell 2004; Poncet \& Gaillard 2010; Mizani et al. 2013; Adkins et al. 2014; Wells et al. 2015). This high-solids inline process is at present poorly understood. Some technologists are concerned that short-term gains in water return are balanced by structures that persist and limit consolidation, but if that is 
so, it potentially offers rehabilitation benefits. If such advantages can be proved and even enhanced, it provides impetus for wider application.

There is very little information available on the impact of polymer molecular weight (MW) on dewatering performance and consolidation behaviour that is of direct relevance to inline flocculation in the minerals industry (Watson et al. 2011a, b). The belief is that this process involves the formation of significantly different aggregate structures than those formed in gravity thickeners, as well as time-based changes to these structures following deposition.

The issues associated with the small-scale testing of polymer reagents (Fawell et al. 2015) are further heightened in high-solids tailings applications. There are several research challenges that need to be addressed: (i) a multitude of interconnected factors exist that can affect water release, necessitating a design-of-experiments approach for identifying interactions, (ii) failure of small-scale testing with beakers, plungers and mechanical stirrers to precisely simulate field conditions, and (iii) poor control over the properties of the treated solids due to irreproducible mixing and dispersion of viscous polymer solutions in dense tailings suspensions. These limitations are evident in many small-scale studies in this area, such that the sensitivity to differences between polymers may be reduced or even masked by mixing effects. Wide shear rate distributions in impeller-driven vessels can lead to significant variations in treated tailings characteristics for duplicate tests. If the issues associated with optimisation of mixing can be resolved, there is then scope to properly identify reagent properties for optimum dewatering and consolidation performance. Given the high dosages being applied for inline flocculation, the scope for optimisation may be considerable and potentially highly valuable.

The focus of this work has therefore been on the production of well-characterised, repeatable thickened clay-based slurries by applying longer conditioning times in a low-shear topological mixer. Mixing is consistent across this vessel, with the uniform shear history allowing polymer properties to be properly identified that maximise net water release and final consolidation levels.

The objectives were: (i) to determine the mixing requirements for polymers of fixed charge density but different MWs, (ii) to establish if aggregate structures created during inline tailings flocculation persist during long-term weathering and consolidation, and conceptualise if this can be utilised to advantage in rehabilitation procedures, and (iii) to identify options that may enhance such effects, whether that be through polymer selection or the addition of other materials after polymer dosing.

\section{Methodology}

\subsection{Polymer solution and slurry preparation}

BASF's experts synthesised a set of anionic polyacrylamides of a fixed charge density (30\%) that span a distinct range of MWs, as characterised by intrinsic viscosity $\left(9.1,10.3,12.2,15.4,17.2,18.5\right.$ and $19.6 \mathrm{dL} \mathrm{g}^{-1}$ for the seven polymers studied) (Costine et al. 2016). To prepare working polymer solutions (0.4 to $1.0 \mathrm{wt} \%$ ), the appropriate mass of dry powder polymer was added to the vortex produced in deionised water by an overhead stirrer at $250 \mathrm{rpm}$ (A310 impeller). Rapid stirring continued for $30 \mathrm{~min}$, with stirring then reduced to a rate that gave continuous movement of the solution $(80 \mathrm{rpm})$. This gentle agitation was maintained for $16 \mathrm{hrs}$. Working polymer concentrations were chosen to maintain a constant solution viscosity (and minimise dispersion effects), such that low MW polymers were applied at a higher concentration than the high MW polymers.

A tailings analogue was prepared at $50 \mathrm{wt} \%$ solids from a combination of kaolin (Prestige NY Australia), silica 200G silt (93\% finer than $53 \mu \mathrm{m}$ ), and silica fine sand (99\% finer than $0.3 \mathrm{~mm}$ ) (both produced by Sibelco Australia Ltd) (Reid \& Fourie 2016). The proportion of each component was $25 \%$ kaolin, $45 \%$ silica 200 G silt, and $30 \%$ silica fine sand by dry mass. During mixing, $2 \mathrm{~g}$ of $\mathrm{NaCl}$ per litre of slurry was added to increase the dissolved solids to a range more typical of a tailings process fluid. The slurry was agitated at $250 \mathrm{rpm}$ for $16 \mathrm{hrs}$ and allowed to equilibrate for seven days before use. It should be noted that the tailings analogue was prepared without the addition of polymer, which would be expected to give some low-level residual structure 
after shearing. Preliminary work to identify mixing conditions that maximised water recovery after polymer treatment used pure kaolin slurry (20 to $30 \mathrm{wt} \%$ ) prepared in a similar manner to the tailings analogue.

\subsection{High-solids polymer addition}

To start an experiment, slurry and polymer solution at the desired flowrates were pumped through a series of $7.7 \mathrm{~mm}$ ID stainless steel coils that could be joined to give any combined length between 0.5 to $22 \mathrm{~m}$, followed by more quiescent mixing in a $2 \mathrm{~L}$ topological mixer. This tapered shear set-up is shown in Figure 1. The topological mixer imparts uniform mixing through the low-shear braiding motion of seven vertical rods $(28 \times 0.6 \mathrm{~cm})$. Thickened slurry exits the mixer via an angled overflow pipe. The main advantage of this approach over impeller-driven batch mixers is that it gives better control and repeatability in the properties of the conditioned slurry, with the laminar mixing zone in the topological mixer minimising shear-induced aggregate breakage (Finn \& Thiffeault 2007, 2011). Crucially, it allows the effects of polymer properties on dewatering performance and aggregate structures to be better distinguished from mixing effects. When the focused beam reflectance measurement (FBRM) statistics confirm that a stable mixing state had been reached in the topological mixer (constant mean sizes), thickened slurry is collected for a $24 \mathrm{hr}$ gravity drainage test ( $4^{\circ}$ slope), as described elsewhere (Costine et al. 2014). Net water recovery was calculated from a mass balance of the release water and the water remaining within the sediment. After deposition, the inline flocculated slurries were sampled weekly to determine the changes (if any) in aggregate structure (density) and slurry compressibility.

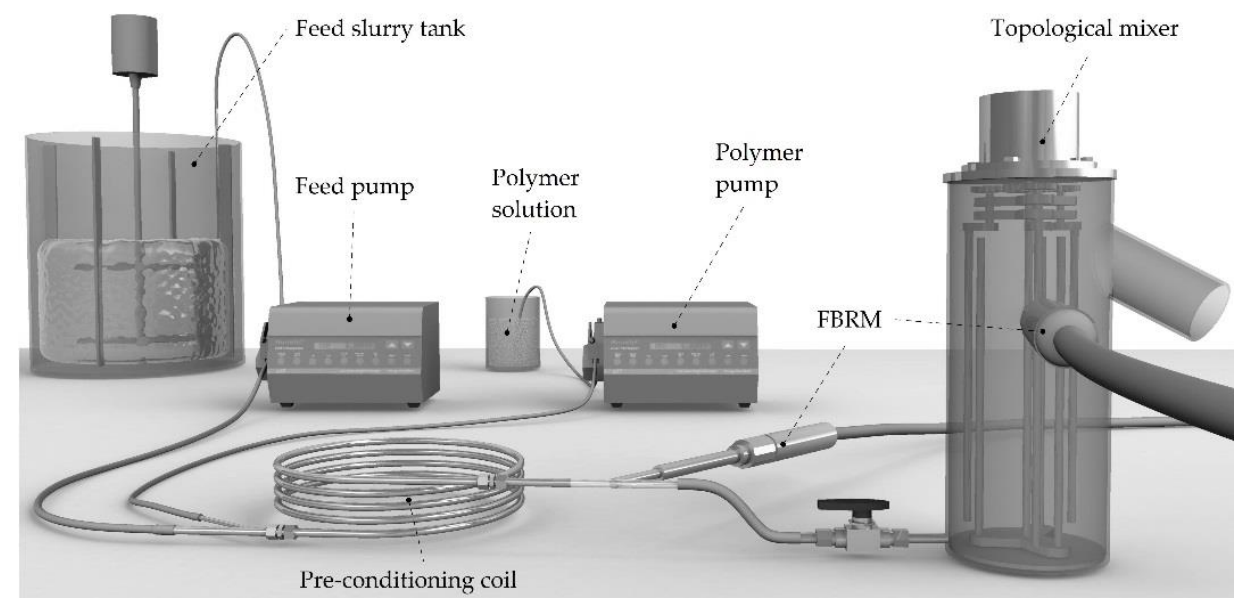

Figure 1 Tapered shear set-up for polymer addition to high-solids suspensions

\subsection{Characterisation techniques}

\subsubsection{Focused beam reflectance measurement}

A Mettler Toledo FBRM model G400 with PI-14/206 probe was used for real-time monitoring of aggregate sizes and fines capture during polymer addition, as described by Heath et al. (2002). FBRM utilises a monochromatic laser beam scanning a circular path and focused at the external surface of a flat sapphire window ( $6 \mathrm{~mm}$ diameter). The probe body joins to a larger casing ( $30 \mathrm{~mm}$ diameter) that contains the electric motor for the scanning drive, which is connected to the controlling electronics in the field unit by a $5 \mathrm{~m}$ fibre optic cable. Reflections from particles or aggregates are measured as pulses when they exceed a threshold intensity, and thousands may be measured every second, generating an unweighted chord length distribution. A chord length is the straight-line distance from one edge of a particle or aggregate to another edge. Using iC FBRM ${ }^{\mathrm{TM}} 4.3$ data acquisition software, scans were measured every 2 sec over the full range of chord lengths ( 1 to $4,000 \mu \mathrm{m}$ ), and averaged over ten measurements when stability had been achieved for the condition being studied. 


\subsubsection{Aggregate density measurements}

The size, settling velocity, and density of individual aggregate structures in the thickened slurry was determined using the floc density analyser (FDA), originally described by Farrow and Warren (1993). Floc density analysis involves capturing images of free settling (i.e. highly diluted) individual aggregates and the measurement of both their size and settling rate. Plots of these free (unhindered) settling rates as a function of size provide a strong indication of aggregate density (Costine et al. 2017), and the density versus size relationships can be derived through application of a modified version of Stokes' law, as described below.

A dilute solids suspension $\left(<0.1 \mathrm{~g} \mathrm{~L}^{-1}\right)$, maintained at $25^{\circ} \mathrm{C}$, was gently resuspended using a perforated disk plunger, and then pumped into a $10 \times 10 \mathrm{~mm}$ analysis cell filled with salt solution $\left(2 \mathrm{~g} \mathrm{~L}^{-1} \mathrm{NaCl}\right)$. The analysis cell was isolated by closing two taps to produce convection-free settling. A digital camera, coupled to selected optical lenses, was used to record images of individual species as they settled under the influence of gravity. The size of individual aggregates was determined by assuming an overall ellipsoidal geometry defined by the maximum horizontal and vertical dimensions measured (with respect to the direction of settling), with the third dimension of the ellipsoidal aggregates assumed to be on average the same as the horizontal dimension. The diameter of the sphere which had a Stokes settling velocity equivalent to the ellipsoid was determined by applying the expressions given by Happel and Brenner (1973). An effective aggregate density was calculated using a terminal velocity equation based on Stokes' Law, from knowledge of the size, settling velocity and the viscosity and density of the fluid. A statistically representative number (at least 400 ) of aggregates covering a broad size range were measured for each sample.

\subsubsection{Compressibility and rheology measurements}

The compressibility of selected inline flocculated slurries was measured using a stepped-pressure filtration rig (Usher et al. 2001). Slurry was pressurised in a compression cell, forcing liquor out through a filter membrane at the cylinder base. The filtration pressure was monitored using a transducer mounted flush in the piston face. Movement of the piston was tracked by a linear encoder with a spatial resolution of $10 \mu \mathrm{m}$. The pressure control system allows pressures ranging from 1 to $400 \mathrm{kPa}$ to be tested. At the conclusion of each increasing pressure step, the resulting cake at its characteristic solids has a compressive yield stress equivalent to the applied pressure.

For selected slurries, the vane yield stresses after deposition were measured with a Haake VT550 rheometer using an FL100 vane controlled at $0.3 \mathrm{rpm}$ for $60 \mathrm{sec}$ by RheoWin Pro software (Thermo Haake GmbH 2017). Inline flocculated slurries were collected in $120 \mathrm{~mL}$ vials having four small holes in their base to allow liquor drainage, but sealed at the top to minimise evaporative drying. Surface water, if present, was decanted before measurement. The final solids concentration was determined after washing and drying the samples.

\section{$3 \quad$ Results and discussion}

\subsection{Design-of-experiments approach for optimising polymer addition}

In preliminary testwork, the effects of several key factors on the dewaterability of a standard kaolin substrate were studied using the tapered shear set-up for polymer addition to high-solids suspensions (Figure 1). The factors investigated were: (i) polymer intrinsic viscosity (seven values between 9 and $20 \mathrm{dL} \mathrm{g}^{-1}$ ), providing a relative indication of polymer MW, (ii) polymer dosage (five values between 400 and 1,200 $\mathrm{g} \mathrm{t}^{-1}$ ), (iii) working polymer concentration (four values between 0.4 and $1.0 \mathrm{wt} \%$ ), (iv) slurry solids concentration (three values between 20 and $30 \mathrm{wt} \%$ ), and ( $\mathrm{v}$ ) mixing duration (five values between 0.5 and $8.5 \mathrm{~min}$ ). The main outputs considered were the initial net water recovery, final solids concentration, yield stress, and FBRM mean sizes and fines capture. A commercially available statistics package, Design-Expert version 9 (Stat-Ease Inc. 2018), was used to develop response surfaces and to interrogate the various datasets for vital interactions and interdependencies. 
One of the critical aspects of this scoping study was the identification of a direct correlation between the main FBRM statistics and net water recovery (defined as the amount of water recovered after $24 \mathrm{hr}$ gravity drainage relative to the amount of water added in the feed slurry and polymer solution, expressed as a percentage). The effect of the resultant measured fines fraction $<10 \mu \mathrm{m}$ and aggregate structures $>1,000 \mu \mathrm{m}$ on kaolin suspension dewaterability is summarised in Figure 2, encompassing the wide range of experimental conditions described previously in this paper. Conditioned slurries with a fines fraction below 2,500 counts and the presence of larger aggregate structures above 400 counts always recorded high water recoveries. It is important to note that whilst the inline injection of polymers to high-solids tailings streams produces aggregate structures larger than the available measurement window ( 1 to $4,000 \mu \mathrm{m})$, it is the combined analysis of both the presence of unaggregated fines and structures $>1,000 \mu \mathrm{m}$ that serves as a useful predictive tool for potential water returns. The photographs of selected inline flocculated slurries after deposition on a $1 \mathrm{~mm}$ screen highlighted the dual requirement of achieving good fines capture and aggregate growth for effective dewatering.

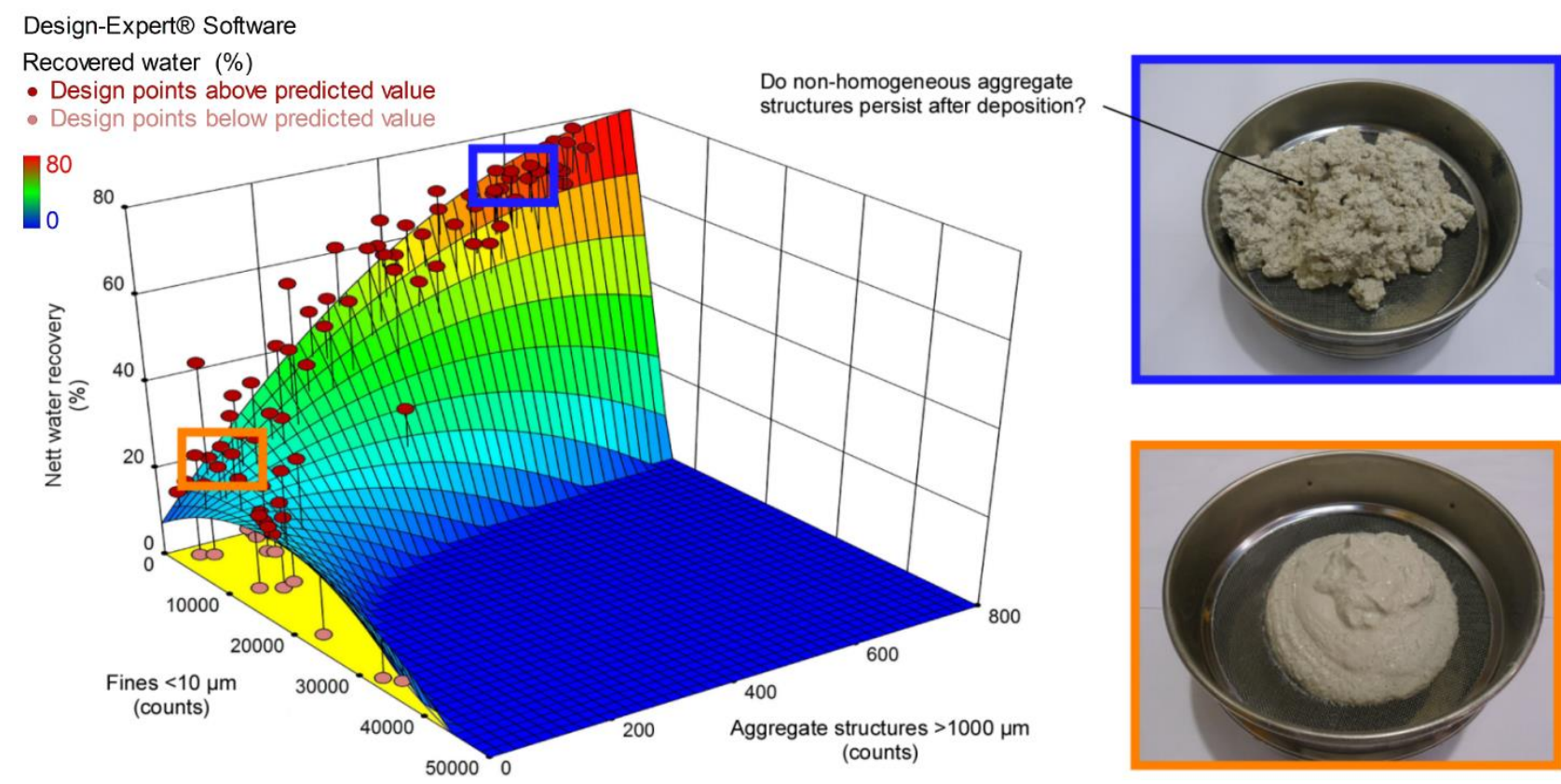

Figure 2 Surface response map showing the effect of fines $<10 \mu \mathrm{m}$ and aggregate structures $>1,000 \mu \mathrm{m}$ on the initial net water recoveries after treating kaolin slurries with polymers over a wide range of experimental conditions

An important outcome from this initial suite of experiments was that polymers with the same chemistry but different MWs had distinctly different mixing requirements to produce the sought-after networked structure on deposition. To assess mixing requirements, working polymer concentrations were chosen to maintain a constant solution viscosity, such that the shorter chain polymers were applied at a higher concentration than longer chains, thereby allowing the effects of polymer MW to be properly evaluated in isolation of dispersion effects.

There are a couple of ways of assessing the effects of initial mixing time in the preconditioning coil (Figure 1) for the different polymers - maintain a constant coil length and vary the flow rate, or keep the flow rate fixed and vary the coil length. The latter approach was preferred because it maintains a steady shear rate with increasing mixing time. The unweighted chord length distributions for kaolin slurry treated with low and high MW polymers are shown in Figure 3 after pre-mixing in the coil and subsequent topological mixing. There are several points of interest from these results: (i) treating high-solids clay slurry in a narrow pipe $(7.7 \mathrm{~mm} \mathrm{ID)} \mathrm{did} \mathrm{not} \mathrm{produce} \mathrm{the} \mathrm{desired} \mathrm{networked} \mathrm{structure,} \mathrm{(ii)} \mathrm{little} \mathrm{difference} \mathrm{was} \mathrm{observed} \mathrm{in} \mathrm{the}$ distributions for different polymer MWs and mixing times in the coil ( 0.5 to $8.5 \mathrm{~min}$ ), and (iii) the main effect of the preconditioning step was to provide a uniform dispersion of adsorbed polymer chains across all particles. 


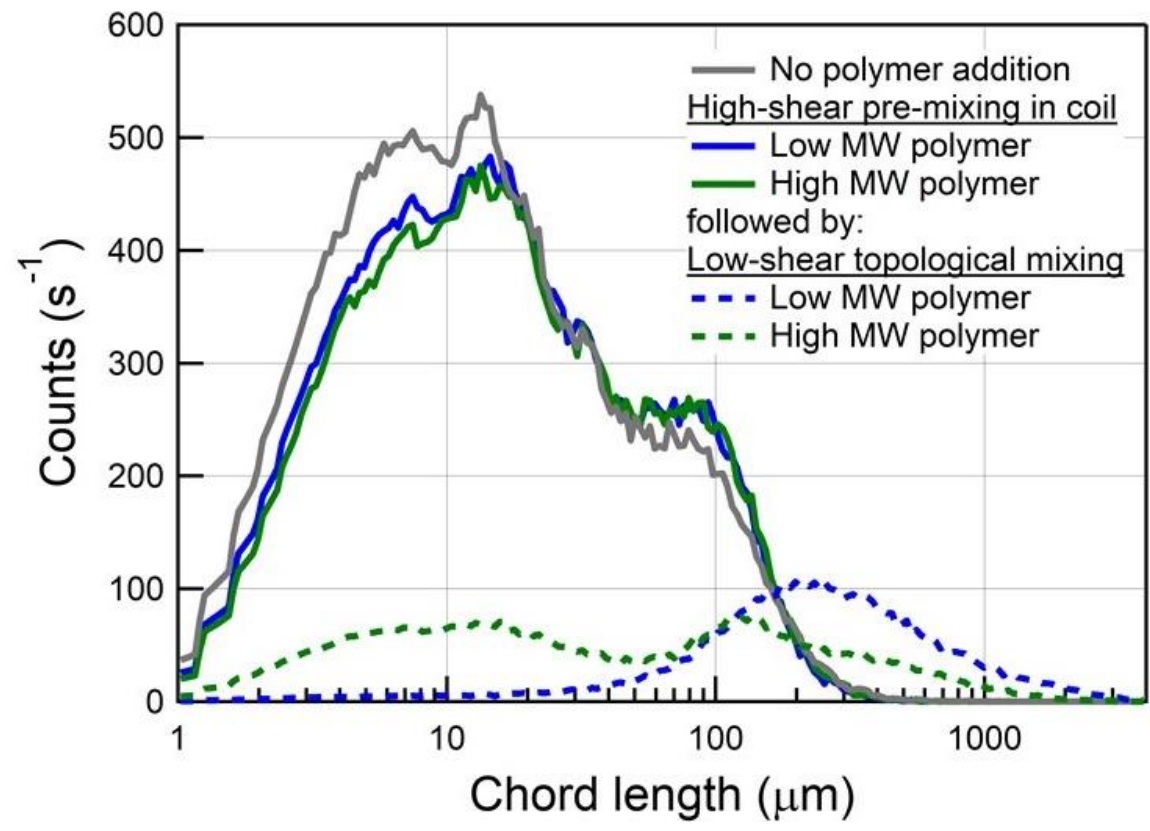

Figure 3 Unweighted FBRM chord length distributions recorded after the preconditioning coil and after the topological mixer (see Figure 1) for kaolin slurry treated with low and high MW polymers (21 wt\% solids, $800 \mathrm{~g} \mathrm{t}^{-1}$, mixing times in the coil and topological mixer were 5 and $4 \mathrm{~min}$, respectively)

Figure 3 shows the same slurries after passing through the preconditioning coil and then undergoing low-shear treatment in the topological mixer (fixed at $4 \mathrm{~min}$ ). The higher energy dispersion environment in the coil provided close contact between the slurry and polymer chains, while the subsequent lower energy conditioning environment minimised any additional shear forces on the existing pre-aggregated material. After topological treatment, inline flocculated slurry was produced with distinctly robust aggregate structures that rapidly expelled water on deposition. The advantage of tapered shear, in which the initial shear is high but is then decreased, is clear as it favours initial mixing of polymer and aggregate formation, but then provides milder conditions to maximise aggregate growth and network formation.

It was also apparent from Figure 3 that the low MW polymer gave better fines capture and produced larger aggregate structures after topological treatment than the high MW polymer. Whilst this was the case after 5 min of pre-mixing, this result should be viewed with some caution as it represents a snapshot of performance after a single mixing time. A more complete picture of the effect of polymer MW was obtained by varying the dosage and pre-mixing time, i.e. by changing the length of the preconditioning coil in Figure 1. Five polymer MWs (with intrinsic viscosities between 9.1 and $19.6 \mathrm{dL} \mathrm{g}^{-1}$ ) were investigated as a function of dosage (three values between 600 and $1,000 \mathrm{~g} \mathrm{t}^{-1}$ ) and pre-mixing time (five values between 0.5 and $8.5 \mathrm{~min}$ ). The corresponding mean sizes and fines content $<10 \mu \mathrm{m}$ under these conditions are summarised in Figure 4 after pre-mixing times of 2,5 , and $8 \mathrm{~min}$ (the time for subsequent treatment in the topological mixer was held constant at $4 \mathrm{~min}$ ). These outputs are good indicators of the potential extent of water recovery after deposition, with mean sizes $>400 \mu \mathrm{m}$ and fines content $<1,000$ counts always giving high water return $(>60 \%$ net water recovery). 

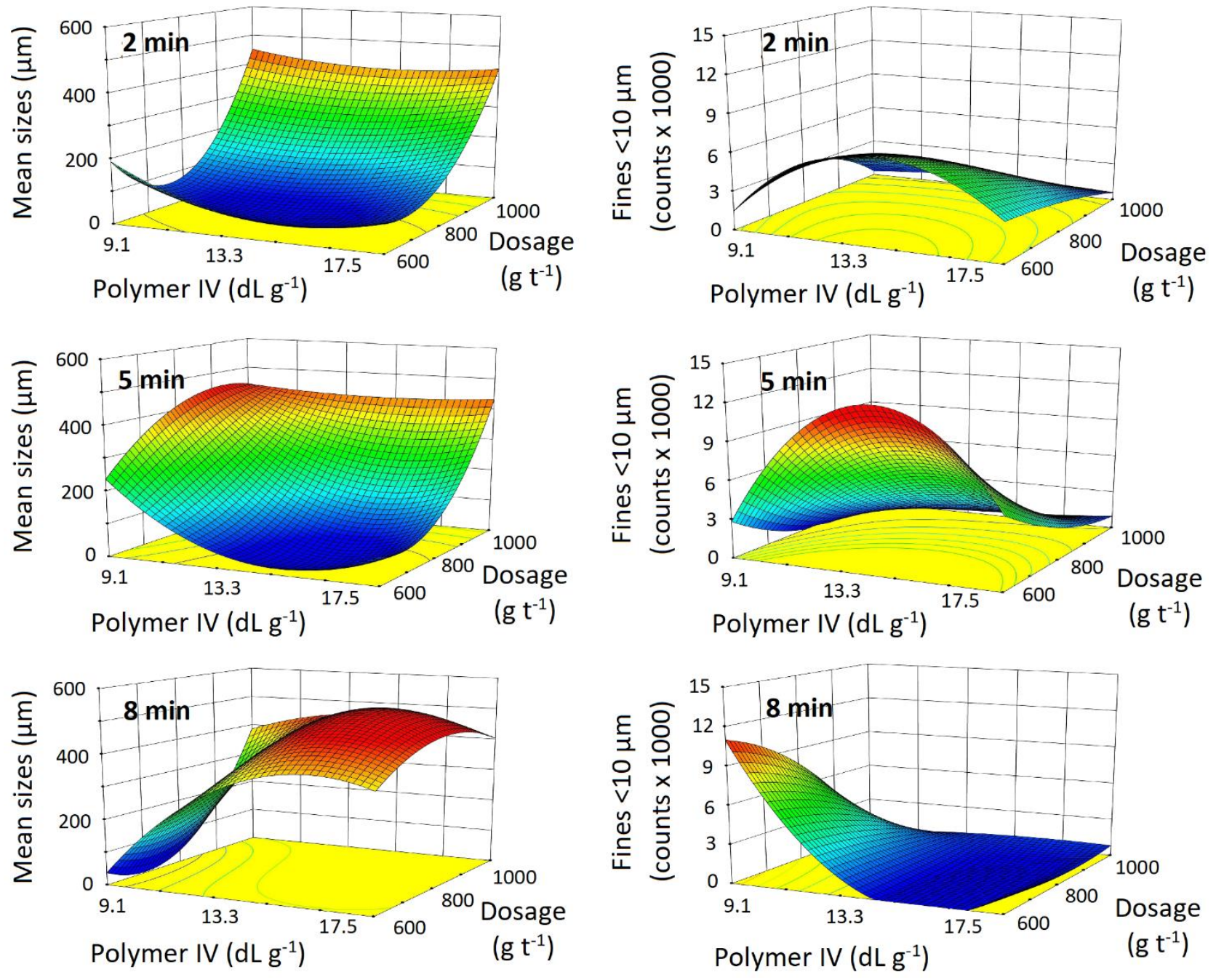

Figure 4 The effect of mixing time in the preconditioning coil (see Figure 1) on the mean sizes and fines capture recorded after topological treatment as a function of polymer intrinsic viscosity (IV) and dosage ( $21 \mathrm{wt} \%$ kaolin, mixing time in the topological mixer was constant at $4 \mathrm{~min}$ )

From this analysis, it is clear that the polymers have distinct mixing requirements. After 2 min, little difference was observed in sizes and fines with varying $\mathrm{MW}$, and high dosages were required for maximum aggregate growth and fines capture $\left(1,000 \mathrm{~g} \mathrm{t}^{-1}\right)$; after $5 \mathrm{~min}$, the low MW polymers gave the most dose-effective response at $\sim 800 \mathrm{~g} \mathrm{t}^{-1}$; after $8 \mathrm{~min}$ of preconditioning, the high $\mathrm{MW}$ polymers performed better even at dosages of $\sim 600 \mathrm{~g} \mathrm{t}^{-1}$. Interpretation of the results is that a polymer that produces more bridges will tolerate and probably require more mixing in high-solids applications, which was only made evident by the multifactor analysis adopted here. Fixing the mixing regime on the basis of what is considered appropriate for a low $\mathrm{MW}$ polymer may lead to suboptimal performance for a high MW polymer, which is more a reflection of the mixing conditions than the polymer's potential performance.

The results in Figures 3 and 4 highlight a couple of the fundamental points of difference between conventional feedwell flocculation (low solids concentration and low dosage) and inline polymer addition (high solids and high dosage):

- With the low solids system, in the absence of additional polymer injection, aggregate breakage would be the dominant process after $5 \mathrm{~min}$ in the preconditioning coil. For the high-solids and high-dosage system, a rigid networked structure was only produced after subsequent topological treatment, indicating that the polymers still retained bridging capacity after $5 \mathrm{~min}$ in the preconditioning coil. The extreme dosages used in the high-solids system undoubtedly act as a blunt instrument, but the results indicate that the initial aggregates formed must be smaller, more 
robust, and denser. The latter point was confirmed using the FDA technique (Costine et al. 2014), which showed that core aggregate structures produced at high dosages are denser than equivalent sizes produced at lower dosages. Aggregated clusters formed at high solids concentrations and high dosages have many more bridging chains and tails, which can rearrange under low-shear conditioning, allowing further densification.

- With conventional feedwell flocculation, initially formed fractal aggregates are further flocculated in a clustering mechanism, and these processes have been studied extensively within the CSIRO laboratories using the coiled pipe reactor and Couette mixing techniques in which the cross-sectional mixing zones are only 7.7 and $5 \mathrm{~mm}$ wide, respectively (e.g. Grabsch et al. 2013; Owen et al. 2007). With inline polymer addition, aggregated clusters require a larger mixing zone to produce a networked structure under low shear (109 $\mathrm{mm}$ in the topological mixer).

Whilst the fundamental processes occurring during inline polymer addition at high solids concentration and high dosages may not be directly comparable with those seen with polymer-bridging flocculation in gravity thickeners, low MW polymers were shown to give a more dose-effective response across both solids regimes when applied under mild fluid shear. Figure 5 shows the dosage-response curves for low and high MW polymers applied in the flocculation of $6 \mathrm{wt} \%$ tailings analogue using a continuous-flow Couette mixing device (Owen et al. 2007). Mudline settling rates were measured after isolating a cylinder of flocculated solids produced under tightly controlled mixing conditions ( $16.5 \mathrm{sec}, 150$ to $400 \mathrm{rpm}$ ). The lower MW polymer compared more favourably with the higher MW under relatively gentle mixing.

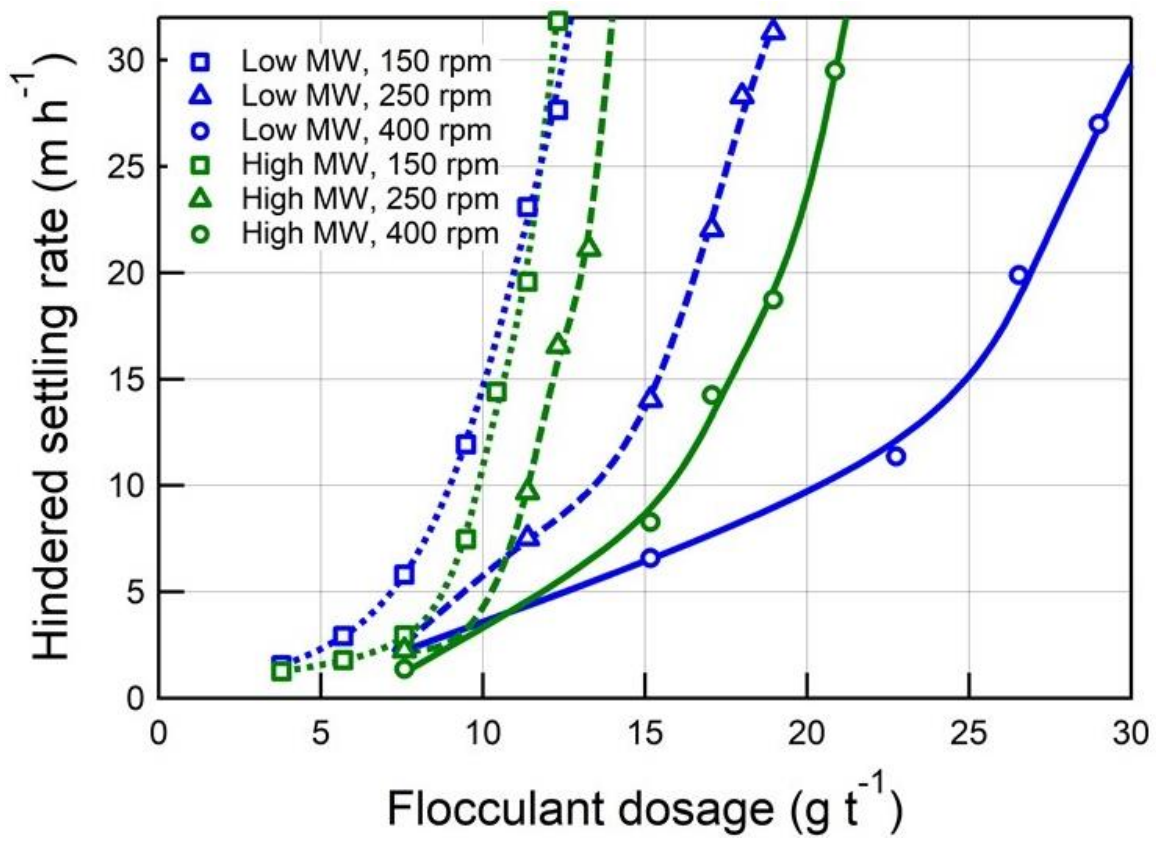

Figure 5 Effect of increasing mixing intensity on the settling rate of low solids tailings analogue treated with low and high MW polymers (6 wt\% solids). Dotted lines $150 \mathrm{rpm}$, dashed lines $250 \mathrm{rpm}$, and solid lines $400 \mathrm{rpm}$

\subsection{Assessing polymer-amended tailings stability}

The preceding testwork in Section 3.1 established a qualitative understanding of the mixing environment required to produce a non-homogeneous networked structure after treating kaolin slurry with different polymer MWs. To determine whether such structures persist after deposition, the tapered shear set-up was used to treat $50 \mathrm{wt} \%$ tailings analogue (comprising of kaolin, silt and fine sand) with low and high MW PAMs applied at $1,000 \mathrm{~g} \mathrm{t}^{-1}$. The conditioning times in the coil and topological mixer were fixed at 2 and 4 min, respectively. In light of the previous work, it is certainly recognised that these conditions are unlikely to represent the most dose-effective utilisation of polymer solution. However, the priority here was to produce 
the desired structure using the same amount of polymer on a mass basis. Inline flocculated slurries were then sampled weekly to determine the effects of ageing and polymer selection on aggregate structure (density), slurry compressibility and rheological behaviour.

For inline flocculated material produced with both PAM polymers, the yield stress increased markedly from 200-900 Pa during the first two weeks of deposition, then plateaued around 1,200 Pa at longer times (Figure 6). The magnitude of these yield stress measurements is consistent with the formation of the sought-after continuous networked structure, which remained largely intact during these ageing experiments. In comparison, the unflocculated material had a vane yield stress of only $9 \mathrm{~Pa}$ and a $24 \mathrm{hr}$ dewatering solids concentration of $49 \mathrm{wt} \%$, highlighting the poor dewatering characteristics in the absence of polymer addition.

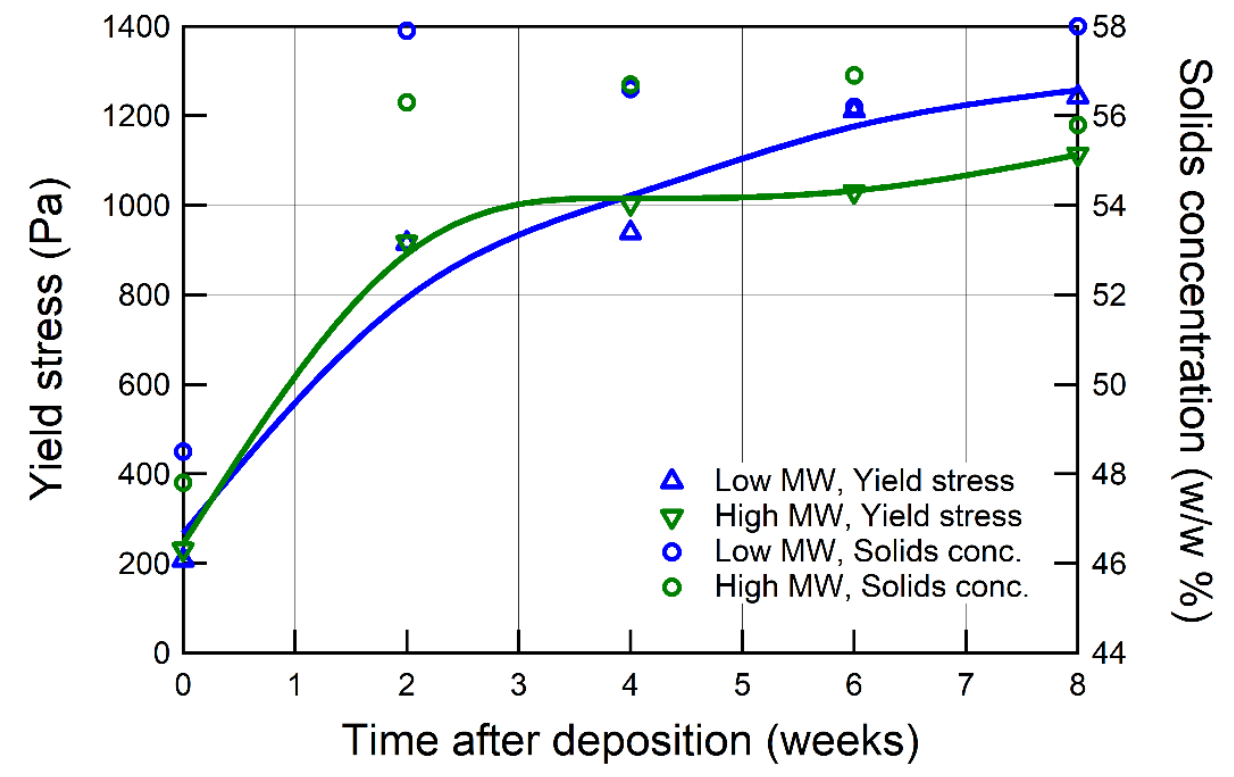

Figure 6 Vane yield stress of inline flocculated slurry produced by low and high MW polymers over an eight week period since deposition (50 wt\% tailings analogue, dosage 1,000 $\mathrm{g} \mathrm{t}^{-1}$ )

The FDA technique was used to assess structural changes in the aggregated material for up to eight weeks after deposition from the low-shear topological mixer. Figure 7 shows free settling rates and densities as a function of size (50-400 $\mu \mathrm{m})$ for individual aggregate structures produced by low and high MW polymers. Aggregate density represents the ratio of the mass enclosed by the ellipsoid (particles and water) to the volume of the ellipsoid.

There was considerable variation in size at a given density due to the polydisperse nature of the primary particles in the clay-based suspension, and the results for each dataset are best compared through the standard fitted curves. Despite this variability, the statistical trend was clear, with the low MW polymer test case producing denser, faster-settling aggregates immediately after deposition $(t=0)$ compared to equivalent sizes produced with the high MW. For example, an average $100 \mu \mathrm{m}$ aggregate for the low $\mathrm{MW}$ polymer test case had a free settling rate of $\sim 4.3 \mathrm{~m} \mathrm{hr}^{-1}$, compared to $\sim 3.0 \mathrm{~m} \mathrm{hr}^{-1}$ for the high MW polymer test case. The corresponding effective aggregate densities were 1.22 and $1.15 \mathrm{~g} \mathrm{~cm}^{-3}$, respectively, indicating that structures produced by the low MW polymer test case under mild mixing had less intra-aggregate liquor than those formed by the high MW polymer test case. For the low MW polymer test case, entrained liquor is expelled as the primary particles are forced closer together by the greater number of shorter chains available. At high polymer dosages, there appears to be a rearrangement of internal aggregate clusters during low-shear conditioning, with the relaxation/contraction of multiple bridging chains leading to further densification. Such effects are most apparent for the longer chains, which are more likely to undergo a slower reconformation because of a higher proportion of loops and tails in the partially adsorbed polymer. 

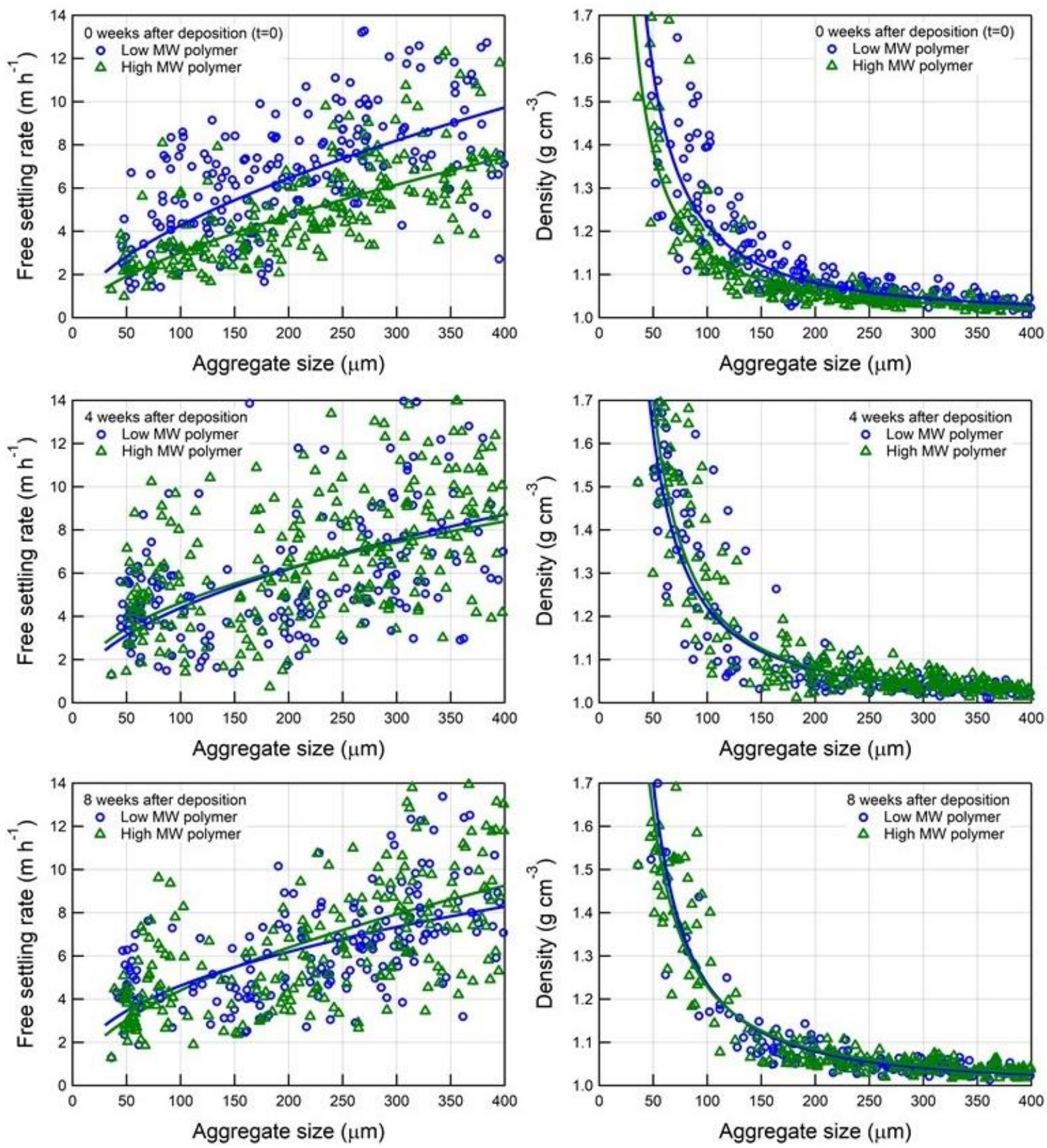

Figure 7 Free settling rate and density versus size as measured by FDA for individual aggregate structures produced by low and high MW polymer test cases over an eight week period since deposition (50 wt $\%$ tailings analogue, dosage $1,000 \mathrm{~g} \mathrm{t}^{-1}$ )

Low-shear conditioning of the concentrated solids stream with elevated dosages of PAM flocculants gave access to larger aggregate structures compared to feedwell flocculation (Costine et al. 2017). The effect of PAM MW was most apparent in the initial deposited material, with similar structures observed for both MWs after longer deposition times. These aggregate structures are distinctly more robust than those formed at low solids concentration using low polymer dosages, with only minor irreversible rupture noted after eight weeks due to some breakdown of high level clusters, but with the core structure remaining intact.

The compressibility of inline flocculated slurries is an important property that influences the final achievable consolidation levels in a tailings storage facility. Ultimately, the compressive yield stress must be exceeded by the self-weight of the overlaying material in order for the tailings to consolidate (Hogg et al. 1995). 
Figure 8 shows temporal changes in the compressive yield stress-volume fraction relationship for inline thickened slurry produced with low and high MW PAM polymers. After polymer treatment, the curves shift left to higher compressive yield stress relative to the untreated slurry. Eight weeks after deposition, the amount of compression required to effect a change in volume was reduced, indicating that a loss of network strength had occurred in the deposited material. After this time, inline flocculated slurry produced with the low MW PAM polymers was characterised by a substantially higher compressive yield stress compared with the high MW PAM polymers (e.g. 215 versus $150 \mathrm{kPa}$, respectively, at a solids volume fraction of $0.60 \mathrm{v} / \mathrm{v}$ ). At a given pressure, the sediment produced by the high $\mathrm{MW}$ reached a higher solids concentration (i.e. was more compressible). This is consistent with the formation of larger (hence weak) aggregate structures by the high MW polymers, as confirmed by real-time sizing by FBRM. This was contrasted by the smaller, more rigid structures accessible through the low MW polymers, as a result of the greater number of shorter chains available when applied at a constant dosage.

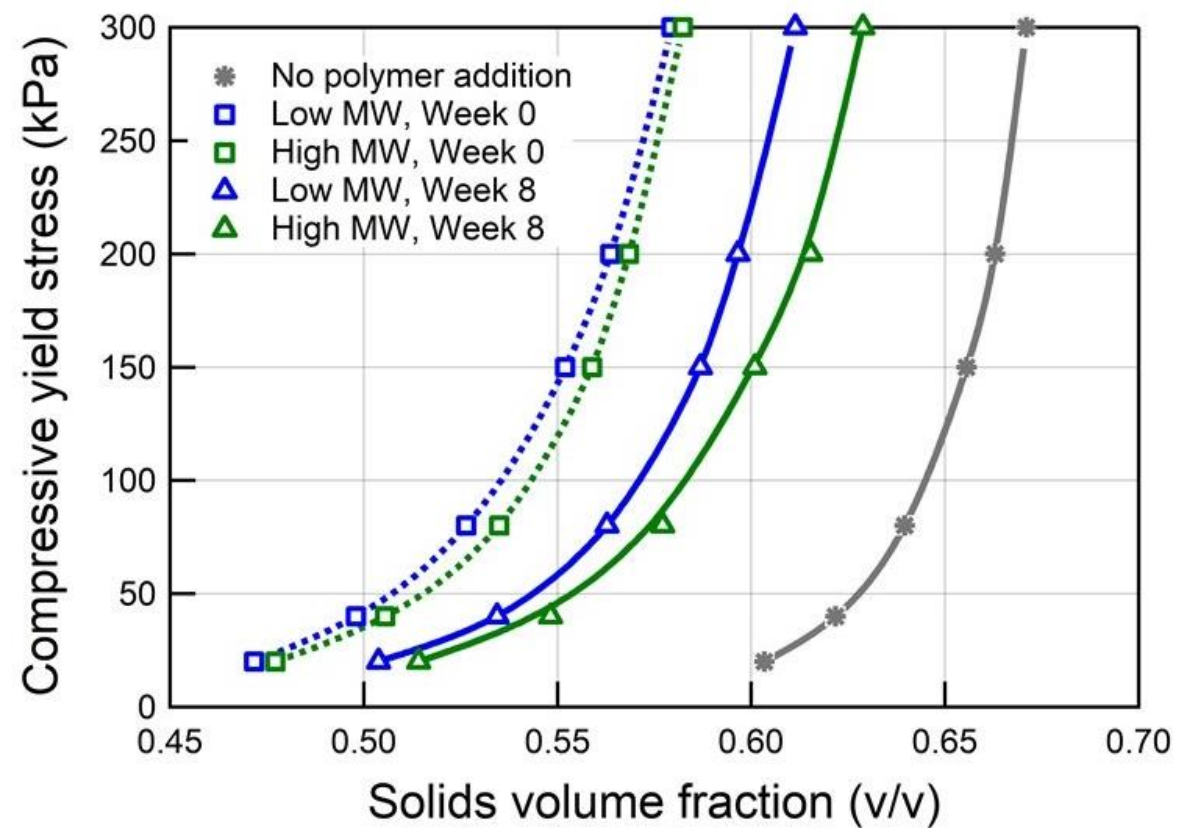

Figure 8 Compressive yield stress of inline flocculated slurry produced by low and high MW polymers over an eight week period since deposition (50 wt\% tailings analogue, dosage $1,000 \mathrm{~g} \mathrm{t}^{-1}$ )

\subsection{Applicability to rehabilitation}

Clearly, the size and structure of the aggregates formed initially during inline polymer addition is a critical factor, affecting the inherent consolidation behaviour of the sediment. The aggregate structure would be expected to vary with the physical properties of the primary particles comprising the feed (e.g. particle size distribution, particle density and shape) and the conditions for polymer addition (e.g. flocculant type and dosage, mixing duration and intensity).

The difference in response to the treatment of tailings using different polymers can be used for the purpose of rehabilitation and functional improvement of tailings properties. Soil science research has shown that the formation of smaller and denser aggregate structures would improve functional properties (Horn \& Smucker 2005), such as the convective flow of water and air if the interaggregate pores are wide enough to create higher pore conductivity and connectivity. The formation of smaller, stronger aggregates could contribute positively to preventing a collapse of the pore system under mechanical loading. Drying of remoulded soils has shown that particles change their position to a state of greater inner energy due to an increase in the capillary forces of water and re-orientation of particles within the available pore space (Dexter 1988; Braunack \& Dexter 1989). At this point, there is uncertainty to what extent the ageing of polymer-treated tailings may similarly alter the pore space. 
These properties, as well as the geochemical stability of the tailings in regard to vegetation establishment and release of potential contaminants, need to be assessed through time-dependent tests. These tests could include measurement of ion exchange reactions which play a critical role in providing available nutrients to plants, as well as plant toxicity. The role of kaolinite and other types of clay and the effect of $\mathrm{pH}$ and ionic strength of the tailings water on physical and chemical stability needs to be investigated.

\section{Conclusion}

Across low and high-solids regimes, lower MW polyacrylamides gave a more dosage-effective response when they were applied under mild mixing, although higher MWs generally gave access to larger sizes. The implementation of low-shear topological mixing for laboratory-scale inline mixing produced large, robust aggregate structures that remained largely intact over the eight week period studied. Variations in the density-size relationship of aggregate structures produced were determined using an image analysis technique, revealing that the shorter polymer chains produced denser, more compact structures immediately after deposition. The effect of ageing on aggregate densification was more pronounced for a high MW polymer, indicating that rearrangement/reconformation of the partially adsorbed flocculant occurred more slowly for the longer chain leading to further densification of the aggregates initially formed. Eight weeks after deposition, inline flocculated slurry produced with the low MW polymer was characterised by a higher compressive yield stress compared with the high $\mathrm{MW}$, consistent with the formation of smaller, more compact aggregate structures with the shorter chains.

\section{References}

Adkins, SJ, Bellwood, J, Beveridge, A, Edgar, M \& Flanagan, IA 2014, 'Differences between secondary flocculation and rigidification via Rheomax ${ }^{\circledR}$-enhanced tailings disposal technology', in RJ Jewell, AB Fourie, PS Wells \& D van Zyl (eds), Proceedings of the 17th International Seminar on Paste and Thickened Tailings, InfoMine Inc., Vancouver, pp. 187-197.

Braunack, MV \& Dexter, AR 1989 'Soil aggregation in the seedbed: a review. I. Properties of aggregates and beds of aggregates', Soil and Tillage Research, vol. 14, no. 3, pp. 259-279.

Costine, A, Lester, D, Fawell, P \& Chryss, A 2014, 'Shear isn't mixing: how to build larger aggregates using chaotic advection for accelerated dewatering', in RJ Jewell, AB Fourie, PS Wells \& D van Zyl (eds), Proceedings of the 17th International Seminar on Paste and Thickened Tailings, InfoMine Inc., Vancouver, p. 644.

Costine, A, Cox, J, Travaglini, S, Lubansky, A, Fawell, P \& Misslitz, H 2016 'Influence of polymer molecular weight in low and high solids tailings applications', in S Barrera \& RJ Jewell, (eds), Proceedings of the 19th International Seminar on Paste and Thickened Tailings, Gecamin, Santiago, chapter 4, paper 2.

Costine, A, Cox, J, Travaglini, S, Lubansky, A, Fawell, P \& Misslitz, H 2017 'Variations in the molecular weight response of anionic polyacrylamides under different flocculation conditions', Chemical Engineering Science, vol. 176, pp. 127-138.

Dexter, AR 1988 'Advances in characterization of soil structure', Soil and Tillage Research, vol. 11, no. 3-4, pp. $199-238$.

Farrow, JB \& Warren, LJ 1993, 'Measurement of the size of aggregates in suspension', in B Dobias (ed.), Coagulation and Flocculation - Theory and Application, Marcel Dekker, New York, pp. 391-426.

Fawell, PD, Costine, AD \& Grabsch, AF 2015, 'Why small-scale testing of reagents goes wrong', in RJ Jewell \& AB Fourie (eds), Proceedings of the 18th International Seminar on Paste and Thickened Tailings, Australian Centre for Geomechanics, Perth, pp. 153-165.

Finn, MD \& Thiffeault, JL 2007, 'Topological entropy of braids on the torus', SIAM Journal on Applied Dynamical Systems, vol. 6, no. 1, pp. 79-98.

Finn, MD \& Thiffeault, JL 2011, 'Topological optimization of rod-stirring devices', SIAM Review, vol. 53, no. 4, pp. 723-743.

Grabsch, AF, Fawell, PD, Adkins, SJ \& Beveridge, A 2013, 'The impact of achieving a higher aggregate density on polymer-bridging flocculation', International Journal of Mineral Processing, vol. 124, pp. 83-94.

Happel, J \& Brenner, H 1973, Low Reynolds Number Hydrodynamics, Noordhoff International Publishing, Leyden.

Heath, AR, Fawell, PD, Bahri, PA \& Swift, JD 2002, 'Estimating average particle size by focused beam reflectance measurement (FBRM)', Particle \& Particle Systems Characterization, vol. 19, no. 2, pp. 84-95.

Hogg, R, Lutsky, M \& Suharyono, H 1995, 'A simulation model For thickening of flocculated, fine-particle suspensions', in JA Herbst (ed.), Proceedings of the XIX International Mineral Processing Congress - Physical \& Chemical Processing, vol. 2, Society for Mining, Metallurgy \& Exploration, Englewood, pp. 81-86.

Horn, R \& Smucker, A 2005, 'Structure formation and its consequences for gas and water transport in unsaturated arable and forest soils', Soil and Tillage Research, vol. 82, no. 1, pp. 5-14.

McColl, P \& Scammell, S 2004, Treatment of Aqueous Suspensions, WO 2004/060819.

Mizani, S, Soleimani, S \& Simms, P 2013, 'Effects of polymer dosage on dewaterability, rheology, and spreadability of polymer-amended mature fine tailings', in RJ Jewell, AB Fourie, J Caldwell \& J Pimenta (eds), Proceedings of the 16th International Seminar on Paste and Thickened Tailings, Australian Centre for Geomechanics, Perth, pp. 117-131. 
Owen, AT, Fawell, PD \& Swift, JD 2007, 'The preparation and ageing of acrylamide/acrylate copolymer flocculant solutions', International Journal of Mineral Processing, vol. 84, pp. 3-14.

Poncet, F \& Gaillard, N 2010, Method for Treating Mineral Sludge Above Ground Using Polymers, US Patent Application No. US2010/0105976.

Reid, D \& Fourie, A 2016, 'Laboratory assessment of the effects of polymer treatment on geotechnical properties of low-plasticity soil slurry', Canadian Geotechnical Journal, vol. 53, pp. 1718-1730.

Stat-Ease Inc. 2018, Design-Expert, version 9, computer software, viewed 21 February 2018, https://www.statease.com/soft-ftp

Thermo Haake GmbH 2017, RheoWin Pro, Thermo Haake GmbH, Karlsruhe.

Usher, SP, De Kretser, RG \& Scales, PJ 2001, 'Validation of a new filtration technique for dewaterability characterization', AICHE Journal, vol. 49, no. 7, pp. 1561-1570.

Watson, P, Farinato, R, Fenderson, T, Hurd, M, Macy, P \& Mahmoudkhani, A 2011a, 'Novel polymeric additives to improve oil sands tailings consolidation', Proceedings of the SPE International Symposium on Oilfield Chemistry, Society of Petroleum Engineers, Richardson, pp. 703-709.

Watson, P, Fenderson, T, Mahmoudkhani, A, Nair, M, Patel, A \& Roberts, G 2011b, 'Breakage and reformation of flocs in oil sands tailings slurries', Proceedings of Tailings and Mine Waste 2011, InfoMine Inc., Vancouver, $10 \mathrm{p}$.

Wells, PS, Charlebois, L, Diep, J, Moyls, B, Omotoso, O, Revington, A \& Weiss, M 2015, 'In-line flocculation', in RJ Jewell \& AB Fourie (eds), Paste and Thickened Tailings - A Guide, 3rd edn, Australian Centre for Geomechanics, Perth, pp. 229-241. 
